\title{
PREPARATION OF ACTIVE ABSORBENT FOR FLUE GAS DESULFURIZATION FROM COAL BOTTOM ASH: EFFECT OF ABSORBENT PREPARATION VARIABLES
}

\author{
Chang Chin Li, Lee Keat Teong, Subhash Bhatia and Abdul Rahman Mohamed* \\ School of Chemical Engineering, Universiti Sains Malaysia, Engineering Campus, 14300 Nibong Tebal, S. P. S., \\ P. Pinang, Malaysia. \\ chrahman@eng.usm.my
}

\begin{abstract}
An active absorbent for flue gas desulfurization was prepared from coal bottom ash, calcium oxide $(\mathrm{CaO})$ and calcium sulfate by hydrothermal process. The absorbent was examined for its micro-structural properties. The experiments conducted were based on Design Of Experiments (DOE) according to $2^{3}$ factorial design. The effect of various absorbent preparation variables such as ratio of $\mathrm{CaO}$ to bottom ash (A), hydration temperature (B) and hydration period (C) towards the BET (Brunauer-Emmett-Teller) specific surface area of the absorbent were studied. At a $\mathrm{CaO}$ to bottom ash ratio $=2$, hydration temperature $=200{ }^{\circ} \mathrm{C}$ and hydration period $=10 \mathrm{hrs}$, absorbent with a surface area of $90.1 \mathrm{~m}^{2} / \mathrm{g}$ was obtained. Based on the analysis of the factorial design, it was concluded that factor $\mathrm{A}$ and $\mathrm{C}$ as well as the interaction of factors $\mathrm{ABC}$ and $\mathrm{BC}$ are the significant factors that effect the BET surface area of the absorbent. A linear mathematical model that describes the relation between the independent variables and interaction between variables towards the BET specific surface area of the absorbent was also developed. Analysis of variance (ANOVA) showed that the model was significant at $1 \%$ level.
\end{abstract}

KEY WORDS : Absorbent, Bottom Ash, Design Of Experiments, Desulfurization, Surface Area.

\section{INTRODUCTION}

In an effort to protect the environment, industrial operations are required to reduce its emission of air pollutants. An air pollutant recognized world wide is sulfur dioxide $\left(\mathrm{SO}_{2}\right)$. The primary source of $\mathrm{SO}_{2}$ are from boilers running on solid and liquid fuels. This is due to the nature of the fuel, where the sulfur compound present in the fuel will react with the air to form $\mathrm{SO}_{2}$ during combustion process in the boiler. Therefore, in order to reduce the emission of $\mathrm{SO}_{2}$, flue gas from the boiler has to be treated with appropriate yet affordable desulfurization technology before being emitted to the environment.

Presently, different types of flue gas desulfurization (FGD) units are being operated. A wet-type FGD unit based on a limestone-gypsum method is most widely used and suitable for large-scale boilers such as those installed in coal or oil-fired power stations. The wettype FGD process has many advantages and has been continuously improved in terms of efficiency and cost reduction. However, as the wet-type FGD process requires a large amount of water and a facility for wastewater treatment, researchers are currently shifting their focus towards developing a dry desulfurization process applicable to power stations in a region where water supply is not sufficient.

Calcium compounds, especially calcium silicate, shows high desulfurization activity in dry FGD processes, due to its high surface area. High surface area in calcium silicate exposed calcium ions in the absorbent for the reaction between $\mathrm{SO}_{2}$ and calcium to occur. Jozewicz and Chang ${ }^{[1]}$ reported that two factors were necessary in an absorbent for it to be readily react with $\mathrm{SO}_{2}$ under the conditions encountered in a dry injection FGD process: (i) high absorbent surface area and (ii) amorphous surface structure. Thus absorbent's high surface area is one of the keys to good desulfurization activity. A number of studies have been carried out to prepare absorbents with high surface area (calcium silicate) from calcium hydroxide and coal fly ash ${ }^{[1-6]}$. The absorbent prepared can achieve a high calcium (Ca) utilization efficiency of $80 \%$, which is much higher than the value of about $50 \%$ for the drytype duct injection process using calcium hydroxide as the $\mathrm{SO}_{2}$ absorbent. However, the weakness of using absorbents prepared from calcium hydroxide and coal fly ash is the long period required for absorbent preparation, which might take up to $12 \mathrm{hrs}$.

In this present study, the effects of substituting calcium hydroxide with calcium oxide and coal fly ash with coal bottom ash as the raw materials for preparation of the absorbent was investigated. The effect of various absorbent preparation variables such as hydration temperature, hydration period and ratio of $\mathrm{CaO}$ to bottom ash towards the BET specific surface area of the absorbent were studied. Design Of Experiments based on full factorial design of $2^{3}$ was used in the present study to establish the significance of each independent variable and interaction between variables. A linear mathematical model that describes the relation between the independent variables and interaction between variables towards the BET specific surface area of the absorbent was also developed. 


\section{MATERIAL AND METHODS}

The absorbent was prepared from calcium sulfate, calcium oxide and coal bottom ash. The calcium sulfate used was of reagent grade, calcium sulfate hemihydrate (BDH Laboratory Supplies, England), whereas the calcium oxide was of laboratory grade (BDH Laboratory Supplies, England). The coal bottom ash was supplied by Kapar Power Plant of Tenaga Nasional Berhad. The bottom ash was thoroughly sieved, to obtain average sizes smaller than $75 \mu \mathrm{m}$. The bottom ash was of the following composition: $\mathrm{SiO}_{2} 42.0 \%$, $\mathrm{Al}_{2} \mathrm{O}_{3} 19.0 \%, \mathrm{CaO} 4.6 \%, \mathrm{Fe}_{2} \mathrm{O}_{3} 9.6 \%, \mathrm{MgO} 2.1 \%, \mathrm{NaO}$ $1.6 \%$ and ignition loss $21.1 \%$.

Standard procedure to prepare the absorbent was as follows. To prepare $20 \mathrm{~g}$ of the absorbent (dry weight), a mixture of coal bottom ash (50\% of the total used) and calcium oxide was mixed with $28-35 \%$ of water at $70{ }^{\circ} \mathrm{C}$ for 5 minutes. Calcium sulfate $(8 \mathrm{~g})$ and the rest of the coal bottom ash were added into the slurry and the kneading were continued for 10 minutes. The kneaded materials were extruded to form pellets. The pellets were then subjected to hydrothermal treatment with steam at a specific temperature for a specific period of time followed by drying for 2 hours at $200{ }^{\circ} \mathrm{C}$. The dried pellets was then crushed and sieved through a $60 \mu \mathrm{m}$ mesh. The amount of chemicals used and experimental parameters are given in Table 1.

Table 1: Experimental design ; hydration parameters and results.

\begin{tabular}{ccccc}
\hline \multirow{2}{*}{$\begin{array}{c}\text { Solid } \\
\text { code }\end{array}$} & $\begin{array}{c}\text { CaO/bottom } \\
\text { ash ratio }\end{array}$ & $\begin{array}{c}\text { Hydriables } \\
\text { temperature } \\
\left({ }^{\circ} \mathrm{C}\right)\end{array}$ & $\begin{array}{c}\text { Hydration } \\
\text { period } \\
(\mathrm{hrs})\end{array}$ & $\begin{array}{c}\text { BET } \\
\text { surface } \\
\text { area } \\
\left(\mathrm{m}^{2} / \mathrm{g}\right)\end{array}$ \\
\hline S1 & $1 / 1$ & 100 & 3 & 6.6 \\
S2 & $2 / 1$ & 100 & 3 & 64.0 \\
S3 & $1 / 1$ & 200 & 3 & 19.7 \\
S4 & $2 / 1$ & 200 & 3 & 26.4 \\
S5 & $1 / 1$ & 100 & 10 & 28.8 \\
S6 & $2 / 1$ & 100 & 10 & 34.1 \\
S7 & $1 / 1$ & 200 & 10 & 17.9 \\
S8 & $2 / 1$ & 200 & 10 & 90.1 \\
S9-I & $1.5 / 1$ & 150 & 6.5 & 43.5 \\
S9-II & $1.5 / 1$ & 150 & 6.5 & 40.5 \\
S9- & $1.5 / 1$ & 150 & 6.5 & 45.2 \\
III & & & & \\
S9- & $1.5 / 1$ & 150 & 6.5 & 42.8 \\
IV & & & & \\
\hline
\end{tabular}

The specific surface area of the absorbent was measured by the BET method using Autosorb 1C Quantachrome. Prior to analyzing the sample, it was degassed at $200{ }^{\circ} \mathrm{C}$ for at least $8 \mathrm{hrs}$. Five-point method was used to estimate the surface area of the prepared absorbent.

\section{RESULTS AND DISCUSSION}

BET surface area for bottom ash, $\mathrm{CaO}, \mathrm{S} 8$ (maximum value of BET specific surface area) and commercial absorbents are given in Table 2. The significant increase in the specific surface area of the hydrated coal bottom ash absorbent as compared to the raw materials suggests that the mixing of the above-shown reagents resulted in the formation of certain compounds with a relatively higher surface area. The hydrated absorbent prepared has a mixture of cylindrical granular grains, which consists predominantly of some calcium aluminate silicate hydrates and $\mathrm{CaO}$. These calcium silicates compounds are the main component in absorbing $\mathrm{SO}_{2}$.

Table 2 BET surface area of raw materials and hydrated absorbents.

\begin{tabular}{cc}
\hline Material & BET surface area $\left(\mathrm{m}^{2} / \mathrm{g}\right)$ \\
\hline Uncalcined bottom ash & 2.45 \\
$\mathrm{CaO}$ & 1.52 \\
Prepared absorbent & 90.1 \\
Commercial absorbent & 64.3 \\
\hline
\end{tabular}

The significant increase in the surface area of the hydrated absorbent also indicates a high structural porosity as compared to the regular $\mathrm{CaO}$. The high surface area of a solid absorbent is an important parameter in the solid-gas adsorption process as it may be one of the principal factors that determine the overall reactivity.

Hydration experiments' based on DOE [7] were employed according to $2^{3}$ factorial design to produce eight different types of absorbent. These combinations allow the studying of the individual influences and their respective interactions of $\mathrm{CaO}$ to bottom ash ratio, hydration temperature and hydration period towards the absorbents' BET specific surface area obtained after hydration. Table 1 shows the experimental design and the results obtained. Four experiments (S9-I to S9-IV) at the center point of the experimental design were performed in order to determine the experimental error.

In relation to the results of BET specific surface area, four main observations can be mentioned : (i) the obtained values range from $6.6 \mathrm{~m}^{2} / \mathrm{g}$ to $90.1 \mathrm{~m}^{2} / \mathrm{g}$; (ii) the highest value is $90.1 \mathrm{~m}^{2} / \mathrm{g}$ corresponding to the experiment $\mathrm{S} 8$ performed at the maximum levels of the hydration variables; $\mathrm{CaO}$ to bottom ash ratio of $2: 1$, hydration temperature of $200^{\circ} \mathrm{C}$ and 10 hours of hydration period ; (iii) $\mathrm{CaO}$ to bottom ash ratio has a significant positive effect on the specific surface area. Higher $\mathrm{CaO}$ to bottom ash ratio was discovered to result in higher specific surface area. This is most probably due to the variation in $\mathrm{pH}$, the concentration and amounts of dissolved solids as increasing the $\mathrm{CaO}$ to bottom ash ratio increases the total amount of dissolved solids and thus the amount of calcium silicate hydrate formed. The presence of crystallized compound, calcium silicate hydrates, also known as oyelite, is important because it contributes to the increase of specific surface area. As the calcium $(\mathrm{Ca})$ ion is the main component of oyelite, it is expected that more $\mathrm{CaO}$ will bring about more of this hydrated compound. It is also known that alkalinity has a positive effect in creating a crystallized structure; and (iv) hydration period and temperature has mixed effects on the BET surface area. 
To study the significance of each independent variable and interaction between variables on the BET surface area, analysis on the factorial design based on the $2^{3}$ full factorial design given in Table 1 was carried out. The three variables studied in this experiment were coded as factor $\mathrm{A}$ for $\mathrm{CaO}$ to bottom ash ratio, factor $\mathrm{B}$ for hydration temperature and factor $\mathrm{C}$ for hydration period. Interaction between factors such as between hydration temperature and hydration period was coded as BC. For 2 level factorial design, the levels of each factor were coded as low or (-1) and high or (1). The coding for all the experiments is given in Table 3 .

For un-replicated factorial design used in this work, a method attributed to Daniel (1959) ${ }^{[8]}$, which suggest the plotting of the effect of a factor on normal probability paper was used. From the probability plot, effects that are negligible are normally distributed, with mean zero and variance $\sigma^{2}$, and will fall along a straight line on this plot, while significant effects will have nonzero means and will not lie along the straight line. The average effect of a factor is defined as the change in response (BET surface area) produced by a change in the level of that factor, averaged over the levels of the other factors while the effect of interaction factors are given elsewhere ${ }^{[7]}$. The effects of the individual factors and interaction between factors were calculated based on the 'YATES' algorithm ${ }^{[7]}$ and tabulated in Table 4. Data for the probability plot is given in Table 5 and the probability plot itself is given in Fig. 1.

Table 3: Coding system used in the factorial design.

\begin{tabular}{lcccccc}
\hline & \multicolumn{3}{c}{ Factors } & \multicolumn{4}{c}{$\begin{array}{c}\text { Coding for } \\
\text { factors }\end{array}$} \\
\cline { 2 - 7 } $\begin{array}{l}\text { Solid } \\
\text { code }\end{array}$ & $\begin{array}{c}\text { CaO/bottom } \\
\text { ash ratio }\end{array}$ & $\begin{array}{c}\text { Hydration } \\
\text { temperature } \\
\left({ }^{\circ} \mathrm{C}\right)\end{array}$ & $\begin{array}{c}\text { Hydration } \\
\text { period } \\
\text { (hrs) }\end{array}$ & A & B & C \\
\hline S1 & $1 / 1$ & 100 & 3 & -1 & -1 & -1 \\
S2 & $2 / 1$ & 100 & 3 & 1 & -1 & -1 \\
S3 & $1 / 1$ & 200 & 3 & -1 & 1 & -1 \\
S4 & $2 / 1$ & 200 & 3 & 1 & 1 & -1 \\
S5 & $1 / 1$ & 100 & 10 & -1 & -1 & 1 \\
S6 & $2 / 1$ & 100 & 10 & 1 & -1 & 1 \\
S7 & $1 / 1$ & 200 & 10 & -1 & 1 & 1 \\
S8 & $2 / 1$ & 200 & 10 & 1 & 1 & 1 \\
\hline
\end{tabular}

Table 4: YATES algorithm for calculating the effects of individual factors and interaction between factors.

\begin{tabular}{ccccccc}
\hline $\begin{array}{l}\text { Solid } \\
\text { code }\end{array}$ & Factors & $\begin{array}{c}\text { BET } \\
\text { surface } \\
\text { area } \\
\left(\mathrm{m}^{2} / \mathrm{g}\right)\end{array}$ & $\begin{array}{c}\text { Column } \\
(1)\end{array}$ & $\begin{array}{c}\text { Column } \\
(2)\end{array}$ & $\begin{array}{c}\text { Column } \\
(3)\end{array}$ & $\begin{array}{c}\text { Estimate } \\
\text { of effect }\end{array}$ \\
\hline S1 & $(l)^{*}$ & 6.6 & 70.6 & 116.7 & 287.5 & - \\
S2 & A & 64.0 & 46.1 & 170.8 & 141.5 & 35.4 \\
S3 & B & 19.7 & 62.8 & 64.1 & 20.7 & 5.2 \\
S4 & AB & 26.4 & 108.0 & 77.4 & 16.3 & 4.1 \\
S5 & C & 28.8 & 57.4 & -24.5 & 54.1 & 13.5 \\
S6 & AC & 34.1 & 6.7 & 45.2 & 13.3 & 3.3 \\
S7 & BC & 17.9 & 5.2 & -50.7 & 69.7 & 17.4 \\
S8 & ABC & 90.1 & 72.2 & 67.0 & 117.7 & 29.4 \\
\hline
\end{tabular}

*(l)- All the factors are low
Table 5: Tabulated data for the probability plot.

\begin{tabular}{cccc}
\hline Order $(\mathrm{j})$ & Factor & Effect & $(\mathrm{j}-0.5) / 7$ \\
\hline 7 & $\mathrm{~A}$ & 35.4 & 0.929 \\
6 & $\mathrm{ABC}$ & 29.4 & 0.786 \\
5 & $\mathrm{BC}$ & 17.4 & 0.643 \\
4 & $\mathrm{C}$ & 13.5 & 0.500 \\
3 & $\mathrm{~B}$ & 5.2 & 0.357 \\
2 & $\mathrm{AB}$ & 4.1 & 0.214 \\
1 & $\mathrm{AC}$ & 3.3 & 0.071 \\
\hline
\end{tabular}

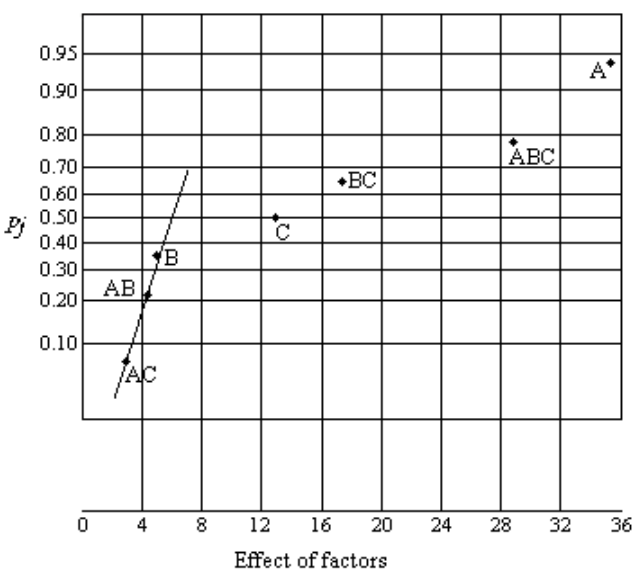

Fig. 1 Ordered effects for the $2^{3}$ factorial design

From Fig. 1, it is noted that factors $\mathrm{A}, \mathrm{ABC}, \mathrm{BC}$ and $\mathrm{C}$ do not fall in a straight line. In other words, factor $\mathrm{A}$ and $\mathrm{C}$ as well as the interaction between factors $\mathrm{BC}$ and $\mathrm{ABC}$ are the main variables that influence the BET surface area of the absorbent. A linear model was developed based on the four factors. The coefficient for the factors are taken from the values of the effect in Table 4. The linear model for the BET surface area is given in Eq. (1):

Surface area $=$

$35.9+\left(\frac{35.4}{2}\right) \mathrm{A}+\left(\frac{13.5}{2}\right) \mathrm{C}+\left(\frac{17.4}{2}\right) \mathrm{BC}+\left(\frac{29.4}{2}\right) \mathrm{ABC}$

where the value $35.9 \mathrm{~m}^{2} / \mathrm{g}$ is the average BET surface area for absorbents with solid code $\mathrm{S} 1$ to $\mathrm{S} 8$ and $\mathrm{A}, \mathrm{C}$, $\mathrm{BC}$ and $\mathrm{ABC}$ are the factors which takes the value of 1 or -1 based on Table 3 .

Table 6 compares the actual values of response (BET specific surface area) with the predicted values obtained from the linear model given in Eq. (1). It can be seen that the model predicts the BET surface area quite accurately with the absolute average percent deviation of less than $10 \%$. To verify the significance of the model and the four main factors that affect the absorbent BET surface area, analysis of variance (ANOVA) was used. Table 7 presents the results of the analysis of variance calculated using Design-Expert 6.0.4 software. Based on the results, it is showed that the model used is significant at $1 \%$ level. It is also shown that the fours factors used in the model are the significant factors at $1 \%$ level that affect the BET surface area of the absorbent. 
Table 6: Comparison between actual and predicted values for BET surface area.

\begin{tabular}{ccccc}
\hline $\begin{array}{c}\text { Solid } \\
\text { code }\end{array}$ & $\begin{array}{c}\text { Actual } \\
\left(\mathrm{m}^{2} / \mathrm{g}\right)\end{array}$ & $\begin{array}{c}\text { Predicted } \\
\left(\mathrm{m}^{2} / \mathrm{g}\right)\end{array}$ & $\begin{array}{c}\text { Residual } \\
\left(\mathrm{m}^{2} / \mathrm{g}\right)\end{array}$ & $\begin{array}{c}\text { Error } \\
(\%)\end{array}$ \\
\hline S1 & 6.6 & 5.5 & 1.1 & 16.7 \\
S2 & 64.0 & 70.3 & -6.3 & 9.8 \\
S3 & 19.7 & 17.5 & 2.2 & 11.2 \\
S4 & 26.4 & 23.4 & 3.0 & 11.4 \\
S5 & 28.8 & 31.0 & -2.2 & 7.6 \\
S6 & 34.1 & 36.9 & -2.8 & 8.2 \\
S7 & 17.9 & 19.0 & -1.1 & 6.1 \\
S8 & 90.1 & 83.8 & 6.3 & 7.0 \\
\hline \multicolumn{4}{r}{ Absolute average percent deviation } & 9.8 \\
\hline
\end{tabular}

Table 7: Analysis of variance for the absorbent BET surface area.

\begin{tabular}{cccccc}
\hline $\begin{array}{c}\text { Source } \\
\text { of } \\
\text { variance }\end{array}$ & $\begin{array}{c}\text { Estimate } \\
\text { of } \\
\text { effects }\end{array}$ & $\begin{array}{c}\text { Sum of } \\
\text { squares }\end{array}$ & $\begin{array}{c}\text { Degrees } \\
\text { of } \\
\text { freedom }\end{array}$ & $\begin{array}{c}\text { Mean } \\
\text { square }\end{array}$ & $F_{o}$ \\
\hline A & 35.4 & 2506.3 & 1 & 2506.3 & $69.4^{\mathrm{a}}$ \\
C & 13.5 & 367.2 & 1 & 367.2 & $10.2^{\mathrm{a}}$ \\
BC & 17.4 & 605.5 & 1 & 605.5 & $16.8^{\mathrm{a}}$ \\
ABC & 29.4 & 1728.7 & 1 & 1728.7 & $47.9^{\mathrm{a}}$ \\
Model & - & 5207.8 & 4 & 1301.9 & $36.1^{\mathrm{a}}$ \\
Residual & - & 108.3 & 3 & 36.1 & - \\
Total & - & 5316.1 & 7 & - & - \\
\hline
\end{tabular}

${ }^{a}$ : significant at $1 \%$ level

For further diagnostic checking of the model, the residual given in Table 6 are plotted on a normal probability paper shown in Fig. 2. The points on this plot lie reasonably close to a straight line, lending support to our conclusion that factors $\mathrm{A}$ and $\mathrm{C}$ as well as the interaction between factors $\mathrm{BC}$ and $\mathrm{ABC}$ are the only significant factors that effect the BET surface area of the absorbent, and that the underlying assumptions of the analysis are satisfied.

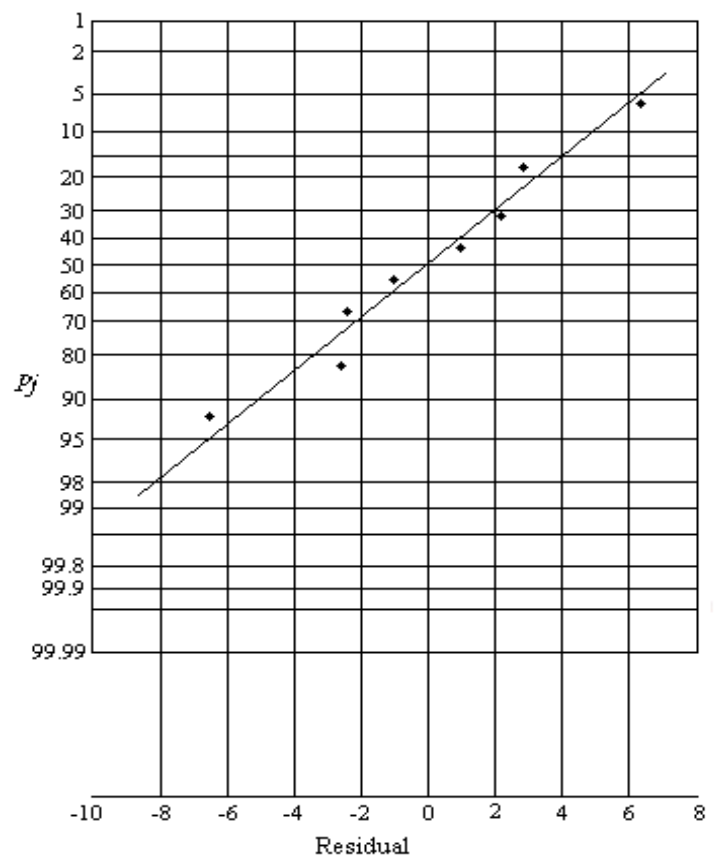

Fig. 2 Normal probability plot of residuals

\section{CONCLUSION}

An investigation established on the preparation of absorbent for dry-type flue gas desulfurization based on utilizing coal bottom ash has been carried out. The following conclusions can be deduced from the results ; (i) Coal bottom ash exhibits a promising future as an absorbent of dry-type flue gas desulfurization and showed potential for highly effective absorbents to be produced commercially (ii) factor $\mathrm{A}, \mathrm{C}$ and the interaction of factors $\mathrm{ABC}$ and $\mathrm{BC}$ are the only significant factors that effect the BET surface area of the absorbents prepared from coal bottom ash, calcium oxide and calcium sulfate.

\section{ACKNOWLEDGEMENT}

We would like to thank Universiti Sains Malaysia for funding this project under an IRPA short term grant.

\section{REFERENCES}

[1] W. Jozewiez and J. C. S. Chang, "Evaluation of FDG injection sorbents and additives", Development of highly reactivity sorbents, Vol. I. EPA-600/7-89-006a, 1989.

[2] A. Garea, I. Fernandez, J. R. Viguri, M. I. Ortiz, J. Fernandez, M. J. Renedo and J. A. Irabien, "Flyash/calcium hydroxide mixtures for SO2 removal : structural properties and maximum yield", Chemical Engineering Journal, Vol. 66, pp. 171-179, 1997.

[3] Y. Li and M. Sadakata, "Study of gypsum formation for appropriate dry desulfurization process of flue gas", Fuel, Vol. 78, pp. 1089-1095, 1999.

[4] T. Ishizuka, H. Tsuchiai, T. Murayama, T. Tanaka and H. Hattori, "Preparation of Active Absorbent for Dry-Type Flue Gas Desulfurization from Calcium Oxide, Coal Fly Ash and Gypsum", Ind. Eng. Chem. Res., Vol. 39, No. 5, pp. 1390-1396, 2000.

[5] T. Ishizuka, T. Yamamoto, T. Murayama, T. Tanaka and H. Hattori, "Effect of Calcium Sulfate Addition on the Activity of the Absorbent for Dry Flue Gas Desulfurization", Energy \& Fuels, Vol. 15, No. 2, pp. 438-443, 2001.

[6] J. Fernandez, M. J. Renedo, A Pesquera and J. A. Irabien, "Effect of CaSO4 on the structure and use of $\mathrm{Ca}(\mathrm{OH}) 2 /$ fly ash sorbents for SO2 removal", Powder Technology, Vol. 119, pp. 201-205, 2001.

[7] D. C. Montgomery, Design And Analysis Of Experiments, John Wiley \& Sons, N.Y., USA 1976.

[8] C. Daniel, "Use of Half-Normal Plots in Interperating Factorial Two Level Experiments", Technometrics, Vol. 1, pp. 311-324, 1959.

\section{NOMENCLATURE}

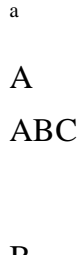

Significant at $1 \%$ level

Ratio of $\mathrm{CaO}$ to bottom ash

Interaction between ratio of $\mathrm{CaO}$ to bottom ash, hydration temperature and hydration period

B 


\begin{tabular}{|c|c|}
\hline BET & Brunauer-Emmett-Teller \\
\hline $\mathrm{BC}$ & $\begin{array}{l}\text { Interaction between hydration } \\
\text { temperature and hydration period }\end{array}$ \\
\hline $\mathrm{C}$ & Hydration period \\
\hline DOE & Design of experiment \\
\hline FGD & Flue gas desulfurization \\
\hline (l) & All the factors are low \\
\hline
\end{tabular}

\section{BIOGRAPHIES}

Chang Chin Li obtained her B. Sc. degree in Chemical Engineering from Universiti Sains Malaysia in 2001. She is currently working with SHELL MALAYSIA as a process engineer. Her long term career plan is to carry out research work in the field of molecular engineering.

Lee Keat Teong obtained his B. Sc. degree in Chemical Engineering from Universiti Sains Malaysia in 2000. He is currently pursuing his $\mathrm{Ph} . \mathrm{D}$ also in Chemical Engineering at Universiti Sains Malaysia under National Science Fellowship from the Ministry of Science, Technology and Environment, Malaysia. His field of research is in air pollution control.
Prof. Subhash Bhatia joined the School of Chemical Engineering, Universiti Sains Malaysia, Perak Branch Campus, in 1995. He was full Professor at the Department of Chemical Engineering, Indian Institute of Technology, Kanpur (India). Prof. Bhatia was a visiting faculty at the University of Queensland, Australia from 1988 - 1989 and 1994 - 1995. His research interests are zeolite catalysis, chemical reaction engineering and environmental catalysis. He has written a book on Zeolite Catalysis that was published by CRC Press, USA and has published more than 75 papers at national and international journals.

Dr. Abdul Rahman Mohamed obtained his Ph.D. in Chemical Engineering from University of New Hampshire. His research interest is mainly in the environmental issues with the emphasis in air pollution control. He is currently the Dean and Associate Professor of the School of Chemical Engineering, Universiti Sains Malaysia. Dr. Abdul Rahman has conducted and completed numerous funded research projects and has published more than 80 papers at various international and national conferences and journals. 
IIUM Engineering Journal, Vol. 2, No. 1, 2001 